\title{
Epstein - Barr virus latent membrane protein 1 suppresses reporter activity through modulation of promyelocytic leukemia protein-nuclear bodies
}

\author{
Mark D Sides ${ }^{1}$, Gregory J Block ${ }^{3}$, Reid W Chadwick', Bin Shan', Erik K Flemington² and Joseph A Lasky ${ }^{1 *}$
}

\begin{abstract}
The Epstein-Barr virus (EBV) encoded Latent Membrane Protein 1 (LMP1) has been shown to increase the expression of promyelocytic leukemia protein (PML) and the immunofluorescent intensity of promyelocytic leukemia nuclear bodies (PML NBs). PML NBs have been implicated in the modulation of transcription and the association of reporter plasmids with PML NBs has been implicated in repression of reporter activity. Additionally, repression of various reporters in the presence of LMP1 has been noted. This study demonstrates that LMP1 suppresses expression of reporter activity in a dose responsive manner and corresponds with the LMP1 induced increase in PML NB intensity. Disruption of PML NBs with arsenic trioxide or a PML siRNA restores reporter activity. These data offer an explanation for previously conflicting data on LMP1 signaling and calls attention to the possibility of false-positives and false-negatives when using reporter assays as a research tool in cells expressing LMP1.
\end{abstract}

Keywords: Latent Membrane Protein 1, Epstein - Barr virus, reporter assay, promyelocytic leukemia protein, promyelocytic leukemia nuclear bodies, arsenic trioxide

\section{Background}

The Epstein -Barr Virus (EBV) encoded Latent Membrane Protein 1 (LMP1) is required for the immortalization of B-cells by EBV, and LMP1 acts as a bona fide oncogene in transforming rodent fibroblast in vitro [1-4]. Structurally, LMP1 is composed of a cytoplasmic $\mathrm{N}$-terminus, six transmembrane domains and a cytoplasmic C-terminus [5]. The $\mathrm{C}$-terminus contains two major signaling domains, $\underline{\mathrm{C}}$-terminus activating regions 1 and 2 (CTAR 1, CTAR 2), which activate NF- $\kappa \mathrm{B}$ [6-8] and p38 [9] signaling pathways through interaction with the effector proteins tumor necrosis factor receptor-associated factors and tumor necrosis factor receptor-associated death domain. LMP1 can also activate ERK signaling through the CTAR 1 domain [10-13], and cjun N-terminus kinase (JNK) through the CTAR 2 domain $[14,15]$ in an NF- $\kappa$ B independent manner. In

\footnotetext{
* Correspondence: jlasky@tulane.edu

'Department of Medicine, Section of Pulmonary Disease and Critical Care, Tulane University School of Medicine, 1430 Tulane Avenue, New Orleans, LA, 70112, USA

Full list of author information is available at the end of the article
}

addition, constitutive activation of the JAK/STAT pathway by LMP-1 has been mapped to 2 Janus kinase binding sites in the region between CTAR 1 and $2[16,17]$.

We have previously shown that LMP1 increases the immunofluorescent intensity of promyelocytic leukemia nuclear bodies (PML NBs) through increased expression of PML protein [18]. The PML NB is a multifunctional proteinaceous nuclear organelle that has been implicated in transcriptional regulation, telomere maintenance, and regulation of apoptosis [19-23]. Although formation of the PML NB is dependent on the PML protein, more than one hundred different proteins have been shown to be recruited to PML NBs, which supports functional heterogeneity of the this nuclear organelle [24]. PML is induced by type I and II interferons $[25,26]$ and has been implicated in antiviral defense [27]. Further, the conserved disruption of PML NBs by alpha, beta, and gamma herpes viruses during lytic reactivation attests to the importance of PML NBs in transcription and the herpesviral lifecycle [28-32]. Increased expression of PML contributes to the maintenance of EBV latency, while arsenic trioxide or PML siRNA disruption of PML 
NBs results in EBV lytic replication, affirming the role of PML in selective transcriptional control [18].

The firefly luciferase gene from Photinus pyralis has been sequenced, and when coupled to promoters of interest, has been a valuable tool to study transcription regulators [33,34]. The rational of the reporter assay assumes that experimental conditions modulate gene expression through binding of transcription complexes to the promoter sequence of interest (e.g.: through activation of transcription factors, etc.). However, expression of LMP1 within the cell or association with PML NBs has been shown to affect reporter activity $[19,35,36]$. In this study, we show that LMP1-mediated suppression of reporter activity is attributable to the upregulation of PML and PML NBs. Disruption of PML NBs by arsenic trioxide or PML siRNA restored reporter activity. These data posit a plausible explanation to reconcile previous conflicting data on LMP1 signaling activity and alerts researcher to the possibility of falsepositives and false-negatives when using reporter assays as screening tools.

\section{Results}

\section{LMP1 suppresses the expression of reporter plasmids}

Expression of LMP1 in A549 cells has been shown to increase transcription of the endogenous MMP9 gene and MMP9 protein levels in an NF $\kappa \mathrm{B}$ dependent manner [37]. Consistent with previous studies, expression of LMP1 increased the levels MMP9 in condition medium (Figure 1A). In contrast, when a reporter construct containing a $700 \mathrm{bp}$ fragment of the MMP 9 promoter region was co-transfected with the LMP1 expression plasmid, LMP1 expression resulted in suppression of reporter activity (Figure 1B). Selective suppression of reporter activity by LMP1 has been previously reported [35], though suppression of reporter activity in that study correlated with suppression of endogenous promoter activity. To further investigate the LMP1 induced disparity between activity on endogenous and exogenous promoters, A549 cells were co-transfected with the LMP1 expression vector and a series of reporter plasmids. Based on previous reports, LMP1 expression was expected to increase AP-1 and NF- $\kappa \mathrm{B}$ responsive reporter activity while having no effect on the constitutive reporters FOP Flash, SV40, pGL3-Control and pRL-TK (renilla luciferase driven by the HSV1 thymadine kinase promoter). LMP1 expression suppressed reporter activity in assays utilizing the LEF/TCF responsive TopFlash reporter, the mutated LEF/TCF control reporter (FopFlash), an NF- $\kappa$ B responsive reporter, an AP1 responsive luciferase reporter construct, and a viral promoter driving $\beta$-galactosidase (SV40) (Figure 1B).

To test whether the suppression of reporter activity by LMP1 was specific to A549 cells, a similar series of

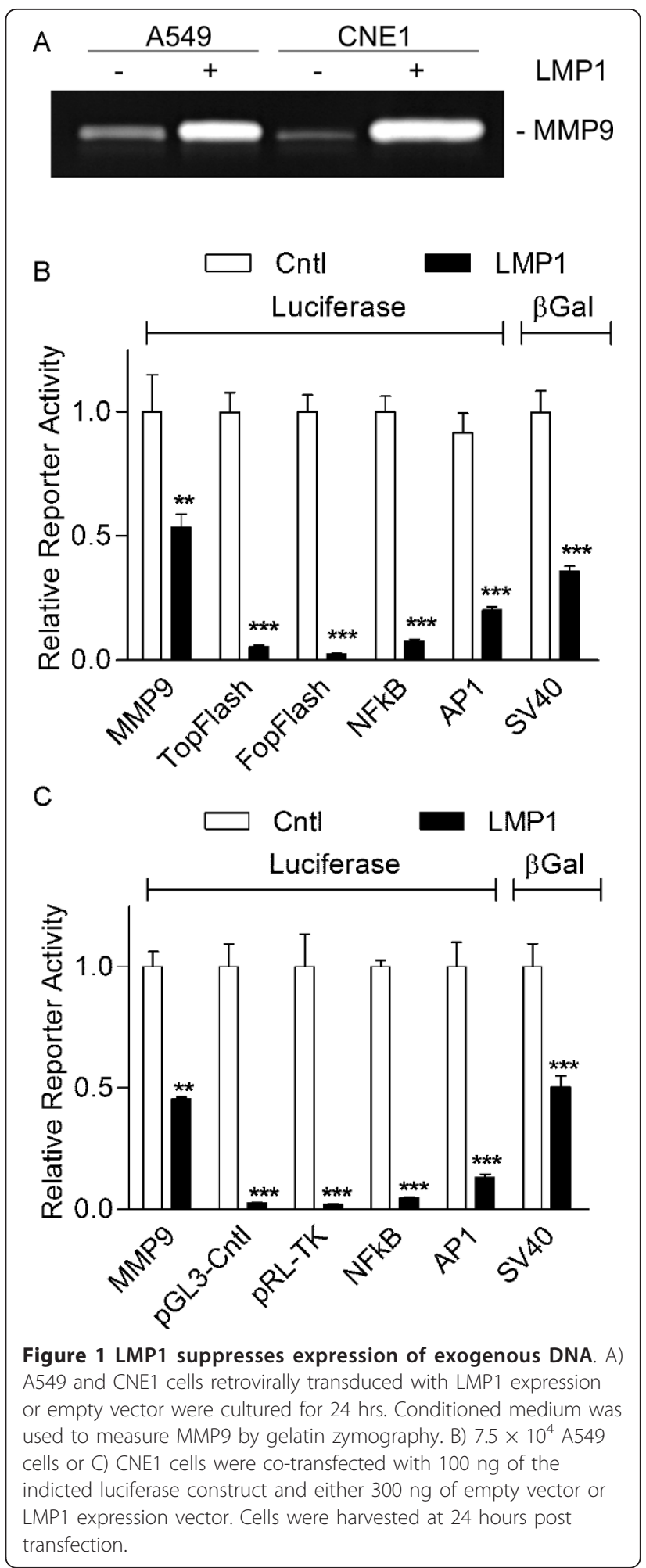

reporter assays were conducted in nasopharyngeal carcinoma cells (CNE-1). LMP1 expression resulted in suppression of reporter activity in each of the constructs utilized (Figure 1C). 


\section{LMP1 suppression of Reporter plasmids is LMP1 dose responsive}

To determine that the effect was not an artifact of transfection efficiency, A549 cells were co-transfected with a constant amount of the $\mathrm{NF} \kappa \mathrm{B}$ responsive reporter along with increasing levels of the LMP1 expression vector (Figure 2A). Very low levels of LMP1 resulted in a modest increase in luciferase activity whereas increasing levels of LMP1 resulted in graded suppression of reporter activity. Reporter activity suppression was also observed when the constitutive firefly construct pGL3 (Figure 2B), the constitutive renilla luciferase reporter containing the HSV1 thymidine kinase promoter (Figure $2 \mathrm{C}$ ), or the firefly luciferase LEF/TCF responsive TopFlash reporter (Figure 2D) were employed in a dual luciferase assay. Notably, when the LEF/TCF responsive data was normalized to the RL-TK data, an artifactual activation was observed (Figure 2E).

Arsenic trioxide disrupts PML NBs in LMP1 positive cells

Arsenic trioxide (ATO) has been shown to induce polyubiquitination dependent proteasomal degradation of PML by directly binding to the conserved RBCC domain [38-40]. To determine the minimal level of ATO needed to disrupt PML NBs in A549 cells, A549 cells retrovirally transduced with LMP1 expression vector or the backbone vector were treated with 1-100 nM ATO for 24 hours and PML NBs were imaged by immunofluorescence. Treatment with ATO produced disruption of PML NBs in a dose dependent manner with complete disruption at a concentration of $10 \mathrm{nM}$ (Figure 3A), whereas cytotoxcicity was noted at doses above $100 \mathrm{nM}$. To investigate whether intact PML NBs are required for LMP1 induced plasmid silencing, A549 cells transduced with an LMP1 retrovirus were transfected with the constitutive reporter pGL3 and treated with varying doses of ATO (Figure 3B). An increase in luciferase activity was seen with the addition of ATO at 1.0 and $10.0 \mathrm{nM}$ concentrations, corresponding with the loss of PML NB immunofluorescence intensity.

ATO restored reporter activity in LMP1 positive cells

To assess the effects of LMP1 expression level on the ability of ATO to restore reporter activity, LMP1 transduced A549 cells were assessed for LMP1 expression (Figure 3C). A549 cells expressing higher and lower levels of LMP1 or transduced with the empty vector were transfected with the constitutive reporter pGL3 Control and treated with $8 \mathrm{nM}$ ATO for 24 . ATO treatment resulted in a 5-fold increase in reporter activity in A549 <LMP1> HI cells, though this level was below that of control. In the A549<LMP1> Lo cells, luciferase activity was completely restored (Figure 3D).

\section{Specific disruption of PML NBs by PML specific SiRNA} restores reporter activity

To preclude possible off target effects by ATO in luciferase restoration assays, PML NBs were disrupted using
siRNA specifically targeted to the PML transcript. Treatment of A549 cells retrovirally transduced with the LMP1 expression vector along with PML specific siRNA resulted in marked though not complete disruption of PML NBs (Figure 4A). In luciferase assays utilizing a viral (pGL3Control and pRL-TK) and cellular (pAP1Luc and p3TP-Lux) reporters transfected into LMP1 positive A549 cells, the addition of PML specific siRNA resulted in a 7 to 17 fold increase in luciferase activity compared to control siRNA (Figure 4B).

\section{Discussion}

A previous report demonstrated that LMP1 induces suppression of some, but not all, reporter constructs, and that reporter suppression correlated with suppression of endogenous gene expression [35]. In the present study, the suppression of reporter activity was independent of the specific promoter used. Importantly, the MMP9 reporter activity did not correlate with the observed LMP-1mediated robust increase in endogenous MMP9 protein expression. The major activation elements in the $M M P 9$ gene promoter are AP-1 and NF- $\kappa \mathrm{B}[41]$, and LMP1 has been shown to increase the expression of endogenous MMP9 in an NF- $\kappa$ B dependent manner [37]. Co-transfection of either AP-1 or NF- $\kappa \mathrm{B}$ responsive reporters along with LMP1, however, resulted in suppression of both reporters. Since LMP1 induces activation of NF-KB signaling through both CTAR1 and CTAR2 (by interacting with TRAF and TRADD) [42] it is predicted that LMP1 should increase $\mathrm{NK}-\kappa \mathrm{B}$ reporter activity in a dose responsive manner. As shown in Figure 2, however, NF- $\kappa$ B dependent reporter activity demonstrated a biphasic response curve resulting in suppression with moderate LMP1 input amounts and abrogation of reporter activity at higher input amounts. These findings may have significant bearing upon the EBV literature. Recently, conflicting data as to the role of LMP1 in the transcription of LEF/TCF responsive genes have been reported based on results from reporter assays [43-45]. The data contained herein may help explain the differences in reported results. When the TopFlash reporter data are normalized to RL-TK in dual luciferase reporter assays, these normalized results are inverse to the un-normalized results and show activation. Similarly, reports of LMP1 suppression of TGF- $\beta 1$ responsive PAI-1 reporter constructs suggested suppression of PAI-1 gene transcription $[46,47]$ while a previous study reported upregulation of PAI-1 by LMP1 $[37,48]$. The observed LMP1 suppression of reporter constructs used in this study was independent of the promoter as even the activity of minimal and constitutive promoters was suppressed. Taken together, these data suggest the possibility of false positives and false negatives when utilizing luciferase assays as a screening tool for LMP1 signaling. 


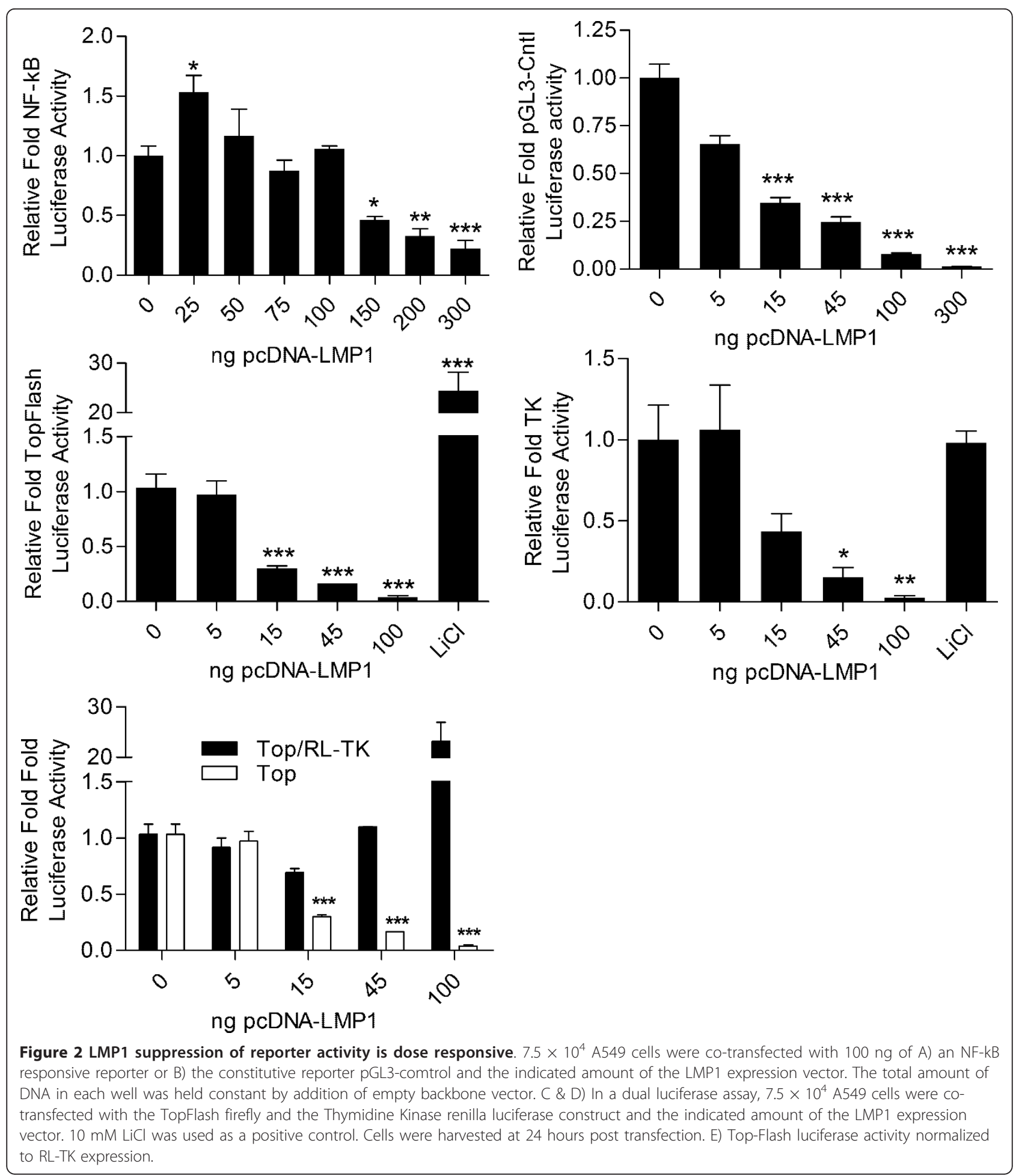

The maintenance of viral latency by LMP1 has been shown to be dependent on upregulation of PML and PML NBs [18]. PML NBs have been implicated in transcriptional control [22] as well as the creation of an antiviral state [27]. Expression of LMP1 increased transcription of the endogenous $M M P 9$ gene while suppressing activity of an $M M P 9$ promoter driven luciferase construct, demonstrating selectivity for LMP1-mediated suppression of ectopic DNA. The suppression of ectopic DNA activity by LMP1 is dependent on upregulation of 

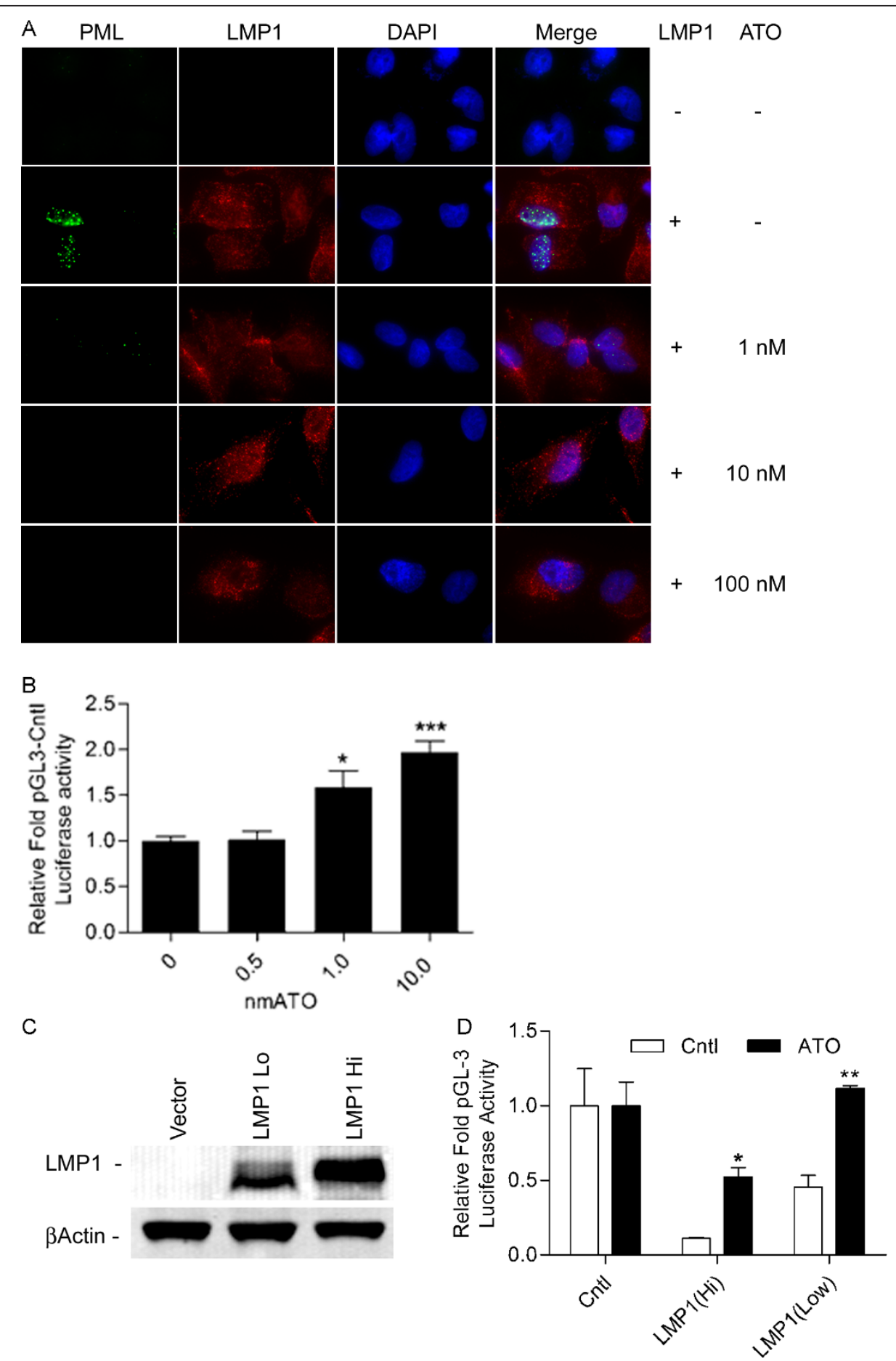

Figure 3 Arsenic trioxide restores expression of exogenous DNA. A) ATO treatment disrupts PML NB. Retrovirally transduced A549 cell expressing LMP1 or a hygromycin resistance cassette (control) were treated for 24 hours with the indicated concentration of ATO and stained for PML (green). Nuclei are stained with DAPI (blue) at original magnification of 600X. B) ATO restores luciferase activity in a dose responsive manner. $7.5 \times 10^{4} \mathrm{~A} 549<\mathrm{LMP} 1>\mathrm{Hi}$ cells were transfected with $100 \mathrm{ng} \mathrm{NF-kB}$ responsive luciferase and treated with the indicated concentration of ATO for 24 hours. C) LMP1 is differentially expressed in separate retroviral transductions. A549 cells were retrovirally transduced with backbone vector expressing only the hygromycin resistance cassette or LMP1 expression vector. Western blot analysis of whole cell lysate of control cells and two separate LMP1 vector transductions; 35 ug of protein was loaded per well. Beta actin was used as a loading control. D) ATO-induced restoration of exogenous DNA expression is LMP1 dose responsive. $7.5 \times 10^{4} \mathrm{~A} 549$ cells retrovirally transduced with backbone vector or 2 separate retroviral transductions differentially expressing LMP1 were transfected with pGL3_Luc and treated with 8 nM ATO for 24 hours. 


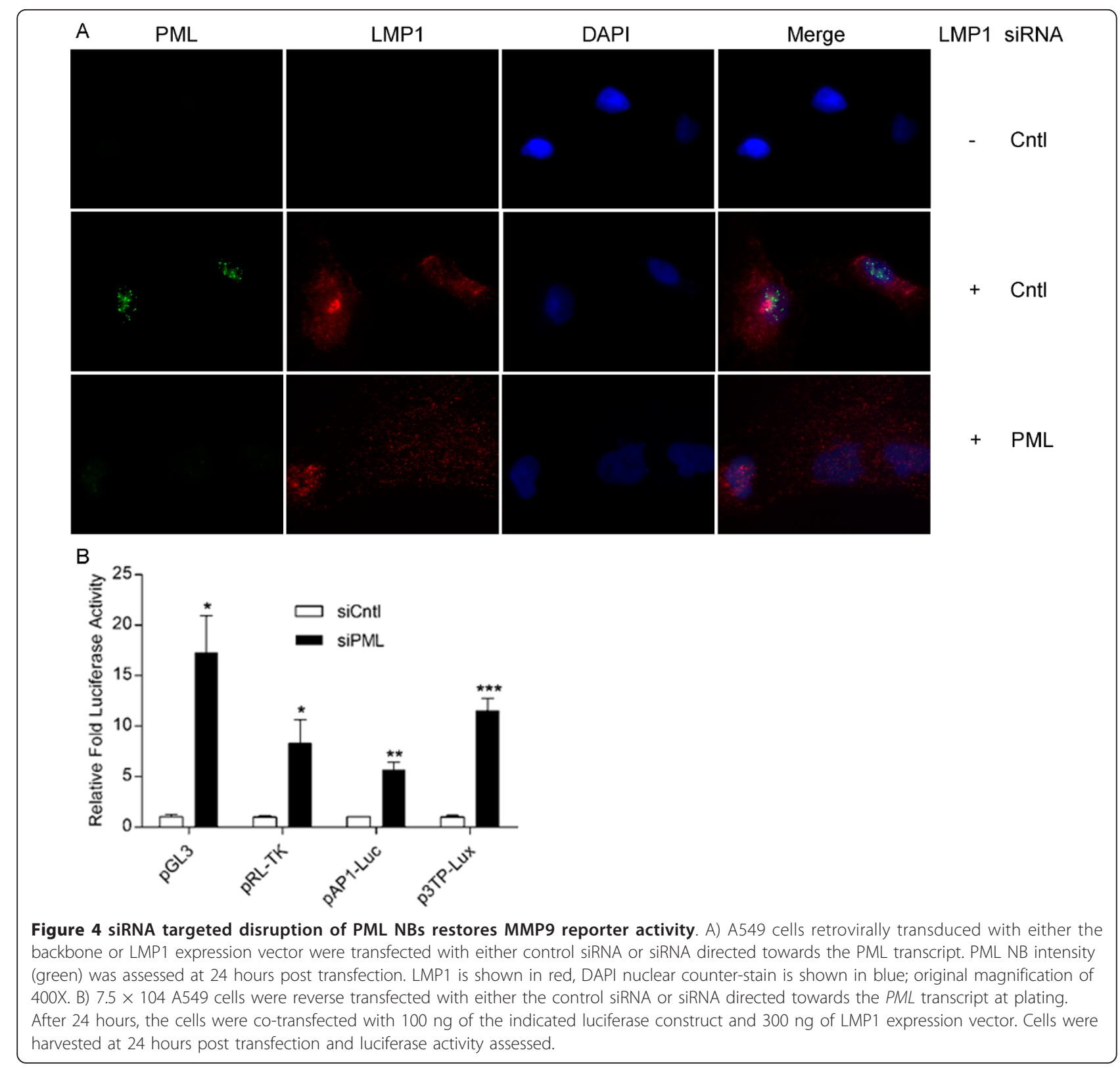

PML NB, as supported by the rescue of luciferase activity with the addition ATO or PML siRNA. The role of PML NB in transcriptional control of certain gene sets has been explored, and data suggests multiple mechanisms are involved $[19,22,23]$. Taken together, these data suggest PML NB's antiviral activity occurs through suppression of ectopic DNA expression.

\section{Materials and methods}

\section{Cell Culture and Transfection}

A549 cells were obtained from ATCC. CNE1 cells were obtained from Samuel H. Speck, (Emory University, Atlanta, Georgia, USA) and have been previously described [49]. All cells were maintained in Dulbecco's minimal essential medium (Invitrogen, Eugene Oregon) supplemented with 10\% fetal bovine serum (Gemini Bio-Products, West Sacramento CA) and 10 units $/ \mathrm{ml}$ penicillin and $10 \mu \mathrm{g} / \mathrm{ml}$ streptomycin (Invitrogen). For transient transfection and luciferase experiments, cells were plated in 24-well plates at an initial density of $7.5 \times 10^{4}$ cells per well and transfected with Lipofectamine (Invitrogen) optimized with Plus reagent (Invitrogen) according to the manufacturer's instructions. During chemical treatment, A549 and A549 derived cells were cultured in DMEM + $0.5 \%$ FBS. 


\section{Generation of Retrovirally Transduced Cells}

Generation of the pEhyg"FLAG*LMP1*wt vector and retroviral transduction of cells have previously been described [50]. Retrovirally transduced cells were maintained in $250 \mu \mathrm{g} / \mathrm{ml}$ hygromycin until 24 hours prior to plating for experiments. In separate infections, differential LMP1 expression was characterized and the two cell lines designated A549 <LMP1> Hi and A549 $<$ LMP1> Lo; control cells were designated A549 $<$ pEhyg $>$.

\section{Plasmids and Reagents}

Arsenic trioxide (ATO) (Sigma Aldrich, St Louis Mo, \#311383) was used at a concentration of $10 \mathrm{nM}$ for treatment of A549 derived cell lines. Lithium Chloride (Sigma) was used at a concentration of $10 \mathrm{mM}$. The pcDNA*Flag"LMP1"wt vector was kindly provided by Nancy Rabb-Traub (UNC-Linberger Cancer Institute). Dominant active $\mathrm{I} \kappa \mathrm{B}$ plasmid has been previously characterized [51] and was a gift from Dean Ballard (Vanderbilt University Medical School, Nashville, TN, USA). The 700 bp promoter region MMP9 luciferase construct (MMP9-Luc) containing two AP-1 responsive sites and one NF- $\kappa$ B responsive site was a gift from Douglas Boyd (MD Anderson Cancer center, Houston, TX, USA), and has been previously characterized [52]. The LEF/TCF responsive reporter $\mathrm{pSu}$ per8TopFlash_Luc containing eight LEF/TCF responsive elements and the control, pSuper8FopFlash_Luc containing mutations in these sites were obtained from AddGene (http://www.addgene.org/) and have been previously described [53]. The NF- $\kappa \mathrm{B}$ responsive reporter construct (pNF $\kappa$ B_Luc), control reporter plasmids pGL-3_Control luciferase and pSV40_bGal b-galactosidase were obtained from Promega (Madison, Wisconsin). The pAP1_Luc reporter construct containing multiple AP1 responsive sequences fused to a TATA-like promoter was obtained from Clonetech (Mountain View, CA).

\section{Luciferase Assays}

For luciferase assays, $7.5 \times 10^{4}$ cells were plated in each well of a 24-well plate, transiently transfected as stated above with $100 \mathrm{ng}$ of the specified reporter plasmid per well, and harvested at 24 hours. For co-transfection and plasmid dose response assays, the total amount of DNA was held constant between wells. Treatment with 10 $\mathrm{mM} \mathrm{LiCl}$ for four hours was used as a positive control for Top-Flash luciferase activity. Luciferase activity was quantified using the Luciferase Assay System (Promega \# E1500) according to manufacturer's protocol, using a single tube luminometer (EG\&G Berthold Lumat LM9507) programmed for a two second delay followed by a ten second read.

\section{Western Blots}

Nuclear and membrane fractions of indicated cell lysates were separated using the Qproteome Cell Compartment Kit (Qiagen, Valencia, CA, \#37502) according to the manufacturer's directions. Briefly, $5 \times 10^{6}$ cells were harvested in proprietary extraction buffer, separated by centrifugation, and the cytosolic fraction (supernatant) was removed. The remaining pellet was resuspended in proprietary extraction buffer, separated by centrifugation, and the membrane fraction (supernatant) was removed. After nuclease treatment, the pellet was resuspended in $500 \mathrm{ul}$ of proprietary extraction buffer, separated by centrifugation, and the nuclear fraction (supernatant) was removed. Nuclear (PML and membrane (LMP1) fractions were combined with 4X Laemmli Buffer ( $240 \mathrm{mM}$ Tris, 8\% SDS, 40\% glycerol, $10 \%$ 2-mercaptoethanol, $0.02 \%$ bromophenol blue) and 30 micrograms of protein per well were loaded in a 10 well NuPage Mops 4-12\% gradient minigel (Invitrogen). Proteins were separated by electrophoresis at $130 \mathrm{~V}$ for 1.5 hours. Separated proteins were transferred for 1.5 hours at $30 \mathrm{~V}$ to PDVF membrane (Invitrogen). Protein transfer was verified by Ponsou-S staining. Membranes were blocked in 5\% BSA in PBST for $1 \mathrm{hr}$ prior to application primary antibody overnight at $4{ }^{\circ} \mathrm{C}$ while shaking at $55 \mathrm{rpm}$. Rabbit polyclonal primary antibody to PML (Santa Cruz Biotechnologies, Santa Cruz, CA, \#sc-5621) was used at a dilution of 1:200. Rabbit polyclonal primary antibody to $\beta$-Actin (Cell Signaling, \#4967) was used at a dilution of 1:1000. Mouse monoclonal primary antibody to LMP1 was (B D Bioscience, Bedford, MA, \#559898) used at a dilution of 1:1000. The secondary antibodies were fluorophore conjugated IRDye 680 goat anti-mouse IgG (LiCor Lincoln, NE, \#926-32220) or IRDye 800CW goat anti-rabbit IgG (LiCor, \#926-32211), and were used at a dilution of 1:15,000. Membranes were imaged using an Odyssey Infrared Imaging System (LiCor).

\section{Immunofluorescence Microscopy}

A549 cells were plated on 8-chambered Lab-Tek slides at $2 \times 10^{4}$ cells per well; chemical treatment began 24 hours after plating. At specified time points, cells were rinsed twice with PBS and fixed in 4\% Paraformaldehyde (freshly diluted from 16\%, Electron Microscopy Science, Hatfield, PA) for $10 \mathrm{~min}$ at room temperature. The cells were then rinsed twice with PBS and permeabilized with 0.5\% Triton X100 (Sigma) in PBS for $15 \mathrm{~min}$ at room temperature. Primary antibodies were applied overnight in a humidified chamber at $4^{\circ} \mathrm{C}$. Following 3 rinses in PBS, secondary antibodies (1:500 dilution) were applied for 1 hour at room temperature. The chambers were removed and Vectashield with DAPI (Vector Laboratories, Burlingame, CA \# H1200) was applied with a 
cover slip mount. The slides were imaged using a Nikon Eclipse 80i microscope and a SensiCam QE camera (Cooke Corporation) and IPLab V3.65a software (Scanalytics). Cells were grown on the same chamber slide and were exposed to the same antibody concentration and wash times. Exposure conditions were optimized for the brightest field of the specified conditions and held constant for subsequent exposures. Primary mouse monoclonal antibody (sc-966) and rabbit polyclonal antibody (sc5621) to PML were purchased from SantaCruz and used at a 1:500 dilution. Primary antibody to LMP1 was purchased from BD Bioscience (\#559898) and used at a dilution of 1:500. Secondary antibodies that were employed were Alexa Fluor 594 goat anti-mouse (Invitrogen \#A11005), AlexaFluor 594 goat anti-rabbit (Invitrogen\#A21207) and AlexaFluor 488 goat anti-mouse (Invitrogen \# A11008) and were as used at a dilution of 1:500.

\section{Statistical Analysis}

Individual comparisons were analyzed by two-tailed unpaired $t$ tests; multiple comparisons were analyzed by ANOVA with Modified Bonferroni post hoc test. A pvalue $<0.05$ was considered significant. For figures, $\left({ }^{*}\right)$ denotes $\mathrm{p}<0.05$ compared to control, $\left({ }^{* *}\right)$ denotes $\mathrm{p}<$ 0.01 compared to control, $(* * *)$ denotes $\mathrm{p}<0.001$ compared to control, (\#) denotes $\mathrm{p}<0.05$ ATO compared to ATO/GCV co-treatment, (\#\#) denotes $\mathrm{p}<0.001$ ATO compared to ATO/GCV co-treatment. The presented data is representative of multiple experiments performed in triplicate. Data is represented as the mean (+/-) SEM.

\footnotetext{
Author details

${ }^{1}$ Department of Medicine, Section of Pulmonary Disease and Critical Care, Tulane University School of Medicine, 1430 Tulane Avenue, New Orleans, LA, 70112, USA. ${ }^{2}$ Department of Pathology, Tulane University School of Medicine, 1430 Tulane Avenue, New Orleans, LA, 70112, USA. ${ }^{3}$ University of Washington Institute for Stem Cell and Regenerative Medicine, 815 Mercer Street, Seattle, WA, 98108, USA.
}

\section{Authors' contributions}

MS conceived of the study, and participated in its design and coordination, carried out experiments, performed data analysis and statistical analysis, GB conceived of the study, participated in its design and coordination, carried out experiments, performed data analysis. RC carried out experiments and participated in data analysis, BS participated in its study design and coordination, EF participated in its study design and coordination, JL conceived of the study, and participated in its design and coordination. All authors read and approved the final manuscript.

\section{Competing interests}

The authors declare that they have no competing interests.

Received: 25 September 2011 Accepted: 5 October 2011 Published: 5 October 2011

\section{References}

1. Moorthy RK, Thorley-Lawson DA: Biochemical, genetic, and functional analyses of the phosphorylation sites on the Epstein-Barr virus-encoded oncogenic latent membrane protein LMP-1. J Virol 1993, 67:2637-2645.
2. Eliopoulos AG, Dawson CW, Mosialos G, Floettmann JE, Rowe M, Armitage RJ, Dawson J, Zapata JM, Kerr DJ, Wakelam MJ, et al: CD40induced growth inhibition in epithelial cells is mimicked by Epstein-Barr Virus-encoded LMP1: involvement of TRAF3 as a common mediator. Oncogene 1996, 13:2243-2254.

3. Peng $M$, Lundgren E: Transient expression of the Epstein-Barr virus LMP1 gene in human primary B cells induces cellular activation and DNA synthesis. Oncogene 1992, 7:1775-1782.

4. Wang D, Liebowitz D, Kieff E: An EBV membrane protein expressed in immortalized lymphocytes transforms established rodent cells. Cell 1985, 43:831-840.

5. Liebowitz D, Wang D, Kieff E: Orientation and patching of the latent infection membrane protein encoded by Epstein-Barr virus. J Virol 1986, 58:233-237.

6. Brodeur SR, Cheng G, Baltimore D, Thorley-Lawson DA: Localization of the major NF-kappaB-activating site and the sole TRAF3 binding site of LMP-1 defines two distinct signaling motifs. J Biol Chem 1997 272:19777-19784.

7. Mosialos G, Birkenbach M, Yalamanchili R, VanArsdale T, Ware C, Kieff E: The Epstein-Barr virus transforming protein LMP1 engages signaling proteins for the tumor necrosis factor receptor family. Cell 1995, 80:389-399.

8. Sandberg M, Hammerschmidt W, Sugden B: Characterization of LMP-1's association with TRAF1, TRAF2, and TRAF3. J Virol 1997, 71:4649-4656.

9. Eliopoulos AG, Gallagher NJ, Blake SM, Dawson CW, Young LS: Activation of the p38 mitogen-activated protein kinase pathway by Epstein-Barr virus-encoded latent membrane protein 1 coregulates interleukin- 6 and interleukin-8 production. J Biol Chem 1999, 274:16085-16096.

10. Dawson CW, Laverick L, Morris MA, Tramoutanis G, Young LS: Epstein-Barr virus-encoded LMP1 regulates epithelial cell motility and invasion via the ERK-MAPK pathway. J Virol 2008, 82:3654-3664.

11. Liu LT, Peng JP, Chang HC, Hung WC: RECK is a target of Epstein-Barr virus latent membrane protein 1. Oncogene 2003, 22:8263-8270.

12. Vaysberg M, Lambert SL, Krams SM, Martinez OM: Activation of the JAK/ STAT pathway in Epstein Barr virus+-associated posttransplant lymphoproliferative disease: role of interferon-gamma. Am J Transplant 2009, 9:2292-2302.

13. Vaysberg M, Hatton O, Lambert SL, Snow AL, Wong B, Krams SM, Martinez OM: Tumor-derived variants of Epstein-Barr virus latent membrane protein 1 induce sustained Erk activation and c-Fos. J Biol Chem 2008, 283:36573-36585.

14. Eliopoulos AG, Blake SM, Floettmann JE, Rowe M, Young LS: Epstein-Barr virus-encoded latent membrane protein 1 activates the JNK pathway through its extreme $C$ terminus via a mechanism involving TRADD and TRAF2. J Virol 1999, 73:1023-1035.

15. Eliopoulos AG, Young LS: Activation of the cJun N-terminal kinase (JNK) pathway by the Epstein-Barr virus-encoded latent membrane protein 1 (LMP1). Oncogene 1998, 16:1731-1742.

16. Chen H, Hutt-Fletcher L, Cao L, Hayward SD: A positive autoregulatory loop of LMP1 expression and STAT activation in epithelial cells latently infected with Epstein-Barr virus. J Virol 2003, 77:4139-4148.

17. Zhang L, Hong K, Zhang J, Pagano JS: Multiple signal transducers and activators of transcription are induced by EBV LMP-1. Virology 2004, 323:141-152.

18. Sides MD, Block GJ, Shan B, Esteves KC, Lin Z, Flemington EK, Lasky JA: Arsenic mediated disruption of promyelocytic leukemia protein nuclear bodies induces ganciclovir susceptibility in Epstein-Barr positive epithelial cells. Virology 2011, 416:86-97.

19. Block GJ, Eskiw CH, Dellaire G, Bazett-Jones DP: Transcriptional regulation is affected by subnuclear targeting of reporter plasmids to PML nuclear bodies. Mol Cell Biol 2006, 26:8814-8825.

20. Boisvert FM, Hendzel MJ, Bazett-Jones DP: Promyelocytic leukemia (PML) nuclear bodies are protein structures that do not accumulate RNA. J Cell Biol 2000, 148:283-292.

21. Yeager TR, Neumann AA, Englezou A, Huschtscha LI, Noble JR, Reddel RR: Telomerase-negative immortalized human cells contain a novel type of promyelocytic leukemia (PML) body. Cancer Res 1999, 59:4175-4179.

22. Bernardi R, Pandolfi PP: Structure, dynamics and functions of promyelocytic leukaemia nuclear bodies. Nat Rev Mol Cell Biol 2007, 8:1006-1016

23. Lallemand-Breitenbach V, de The H: PML nuclear bodies. Cold Spring Harb Perspect Biol 2010, 2:a000661. 
24. Van Damme E, Laukens K, Dang TH, Van Ostade X: A manually curated network of the PML nuclear body interactome reveals an important role for PML-NBs in SUMOylation dynamics. Int J Biol Sci 2010, 6:51-67.

25. Lavau C, Marchio A, Fagioli M, Jansen J, Falini B, Lebon P, Grosveld F, Pandolfi PP, Pelicci PG, Dejean A: The acute promyelocytic leukaemiaassociated PML gene is induced by interferon. Oncogene 1995, 11:871-876.

26. Stadler M, Chelbi-Alix MK, Koken MH, Venturini L, Lee C, Saib A, Quignon F, Pelicano L, Guillemin MC, Schindler C, et al: Transcriptional induction of the PML growth suppressor gene by interferons is mediated through an ISRE and a GAS element. Oncogene 1995, 11:2565-2573.

27. Everett RD, Chelbi-Alix MK: PML and PML nuclear bodies: implications in antiviral defence. Biochimie 2007, 89:819-830.

28. Maul GG, Everett RD: The nuclear location of PML, a cellular member of the $\mathrm{C} 3 \mathrm{HC} 4$ zinc-binding domain protein family, is rearranged during herpes simplex virus infection by the $\mathrm{C} 3 \mathrm{HC} 4$ viral protein ICP0. J Gen Virol 1994, 75(Pt 6):1223-1233.

29. Maul GG, Guldner HH, Spivack JG: Modification of discrete nuclear domains induced by herpes simplex virus type 1 immediate early gene 1 product (ICP0). J Gen Virol 1993, 74(Pt 12):2679-2690.

30. Everett RD, Maul GG: HSV-1 IE protein Vmw110 causes redistribution of PML. EMBO J 1994, 13:5062-5069.

31. Kelly C, Van Driel R, Wilkinson GW: Disruption of PML-associated nuclear bodies during human cytomegalovirus infection. J Gen Virol 1995, 76(Pt 11):2887-2893.

32. Adamson AL, Kenney S: Epstein-barr virus immediate-early protein BZLF1 is SUMO-1 modified and disrupts promyelocytic leukemia bodies. J Virol 2001, 75:2388-2399.

33. de Wet JR, Wood KV, DeLuca M, Helinski DR, Subramani S: Firefly luciferase gene: structure and expression in mammalian cells. Mol Cell Biol 1987, 7:725-737.

34. Brasier AR, Tate JE, Habener JF: Optimized use of the firefly luciferase assay as a reporter gene in mammalian cell lines. Biotechniques 1989, 7:1116-1122.

35. Narbonnet S, Mariame B: The Epstein-Barr virus oncoprotein LMP1 inhibits the activity of viral or cellular promoters without inducing cytostasis. Virology 2006, 350:381-393.

36. Sandberg ML, Kaykas A, Sugden B: Latent membrane protein 1 of EpsteinBarr virus inhibits as well as stimulates gene expression. J Virol 2000, 74:9755-9761.

37. Sides MD, Klingsberg RC, Shan B, Gordon KA, Nguyen HT, Lin Z, Takahashi T, Flemington EK, Lasky JA: The Epstein-Barr Virus LMP 1 and TGF-\{beta\}1 Synergistically Induce EMT in Lung Epithelial Cells. Am J Respir Cell Mol Biol 2010.

38. Zhang XW, Yan XJ, Zhou ZR, Yang FF, Wu ZY, Sun HB, Liang WX, Song AX, Lallemand-Breitenbach $V$, Jeanne $M$, et al: Arsenic trioxide controls the fate of the PML-RARalpha oncoprotein by directly binding PML. Science 2010, 328:240-243.

39. Lallemand-Breitenbach V, Jeanne M, Benhenda S, Nasr R, Lei M, Peres L, Zhou J, Zhu J, Raught B, de The H: Arsenic degrades PML or PMLRARalpha through a SUMO-triggered RNF4/ubiquitin-mediated pathway. Nat Cell Biol 2008, 10:547-555.

40. Weisshaar SR, Keusekotten K, Krause A, Horst C, Springer HM, Gottsche K, Dohmen RJ, Praefcke GJ: Arsenic trioxide stimulates SUMO-2/3 modification leading to RNF4-dependent proteolytic targeting of PML. FEBS Lett 2008, 582:3174-3178.

41. Yan C, Boyd DD: Regulation of matrix metalloproteinase gene expression. J Cell Physiol 2007, 211:19-26.

42. Eliopoulos AG, Young LS: LMP1 structure and signal transduction. Semin Cancer Biol 2001, 11:435-444.

43. Jang KL, Shackelford J, Seo SY, Pagano JS: Up-regulation of beta-catenin by a viral oncogene correlates with inhibition of the seven in absentia homolog 1 in B lymphoma cells. Proc Natl Acad Sci USA 2005, 102:18431-18436.

44. Tomita M, Dewan MZ, Yamamoto N, Kikuchi A, Mori N: Epstein-Barr virusencoded latent membrane protein 1 activates beta-catenin signaling in B lymphocytes. Cancer Sci 2009, 100:807-812.

45. Webb N, Connolly G, Tellam J, Yap AS, Khanna R: Epstein-Barr virus associated modulation of Wnt pathway is not dependent on latent membrane protein-1. PLoS One 2008, 3:e3254.
46. Mori N, Morishita M, Tsukazaki T, Yamamoto N: Repression of Smaddependent transforming growth factor-beta signaling by Epstein-Barr virus latent membrane protein 1 through nuclear factor-kappaB. Int J Cancer 2003, 105:661-668.

47. Prokova $V$, Mosialos $G$, Kardassis $D$ : Inhibition of transforming growth factor beta signaling and Smad-dependent activation of transcription by the Latent Membrane Protein 1 of Epstein-Barr virus. J Biol Chem 2002, 277:9342-9350

48. Kim KR, Yoshizaki T, Miyamori H, Hasegawa K, Horikawa T, Furukawa M, Harada S, Seiki M, Sato H: Transformation of Madin-Darby canine kidney (MDCK) epithelial cells by Epstein-Barr virus latent membrane protein 1 (LMP1) induces expression of Ets1 and invasive growth. Oncogene 2000, 19:1764-1771.

49. LTVCl: Establishment of an Epithelioid Cell Line and a Fusiform Cell Line from a Patient with Nasopharyngeal Carcinoma. Sci Sinica 1978, 21:127.

50. Cameron JE, Yin Q, Fewell C, Lacey M, McBride J, Wang X, Lin Z, Schaefer BC, Flemington EK: Epstein-Barr virus latent membrane protein 1 induces cellular MicroRNA miR-146a, a modulator of lymphocyte signaling pathways. J Virol 2008, 82:1946-1958.

51. Brockman JA, Scherer DC, McKinsey TA, Hall SM, Qi X, Lee WY, Ballard DW: Coupling of a signal response domain in I kappa $B$ alpha to multiple pathways for NF-kappa B activation. Mol Cell Biol 1995, 15:2809-2818.

52. Nair RR, Solway J, Boyd DD: Expression cloning identifies transgelin (SM22) as a novel repressor of 92-kDa type IV collagenase (MMP-9) expression. J Biol Chem 2006, 281:26424-26436.

53. Veeman MT, Slusarski DC, Kaykas A, Louie SH, Moon RT: Zebrafish prickle, a modulator of noncanonical Wnt/Fz signaling, regulates gastrulation movements. Curr Biol 2003, 13:680-685.

doi:10.1186/1743-422X-8-461

Cite this article as: Sides et al:: Epstein - Barr virus latent membrane protein 1 suppresses reporter activity through modulation of promyelocytic leukemia protein-nuclear bodies. Virology Journal 2011 8:461.

\section{Submit your next manuscript to BioMed Central and take full advantage of:}

- Convenient online submission

- Thorough peer review

- No space constraints or color figure charges

- Immediate publication on acceptance

- Inclusion in PubMed, CAS, Scopus and Google Scholar

- Research which is freely available for redistribution 